02

\title{
Исследование эффектов нестационарности при набухании полимерных мембран с помощью фурье ИК спектроскопии
}

\author{
() Н.Ф. Бункин ${ }^{1,2}$, В.А. Козлов ${ }^{1,2}$, М.С. Кирьянова ${ }^{1,2}$, Р.С. Сарроненков ${ }^{1,2}$, П.Н. Болоцкова ${ }^{1,2}$, \\ B.С. Горелик ${ }^{1,3}$, Й. Джураев ${ }^{4}$, Л.М. Сабиров ${ }^{4}$, А.Э. Применко ${ }^{1}$, M.T. Vu ${ }^{1}$ \\ ${ }^{1}$ Московский государственный технический университет им. Н.Э. Баумана, \\ 105005 Москва, Россия \\ ${ }^{2}$ Институт общей фиизики им. А.М. Прохорова РАН, \\ 119991 Москва, Россия \\ ${ }^{3}$ Физический институт им. П.Н. Лебедева РАН, \\ 119991 Москва, Россия \\ ${ }^{4}$ Самаркандский государственный университет, \\ 140104 Самарканд, Республика Узбекистан \\ e-mail: nbunkin@kapella.gpi.ru
}

Поступила в редакцию 24.09.2020 г.

В окончательной редакции 04.12.2020 г.

Принята к публикации 16.12.2020 г.

В экспериментах по ИК фурье-спектроскопии изучен режим набухания полимерной мембраны Нафион в воде, залитой в кювету, характерный размер которой порядка толщины самой мембраны. Интерес к этим исследованиям обусловлен тем фактом, что при набухании Нафиона в кювете, размер которой много больше толщины мембраны, происходит эффективное „разматывание“ полимерных волокон в объем воды. Однако этот процесс не был изучен в случае, когда область, которую могут занять размотанные в объеме жидкости полимерные волокна, ограничена размером кюветы. Показано, что в этом случае временная динамика перехода полимера из гидрофобного в гидрофильное состояние имеет ряд специфических особенностей, которые зависят от размера кюветы, а также от изотопного состава, содержания ионов и предварительной обработки воды.

Ключевые слова: ИК фурье-спектроскопия, коэффициент пропускания, полимерные мембраны, гидрофобность и гидрофильность.

DOI: $10.21883 / O S .2021 .04 .50777 .241-20$

\section{Введение}

В последнее время полимерные мембраны из Нафиона $\left(\mathrm{Nafion}^{\mathrm{TM}}\right)$, разработанного фирмой DuPont, интенсивно исследуются (обзор [1] и приведенные в нем ссылки). Интерес к этим исследованиям связан с применением Нафиона в низкотемпературных водородных элементах [2,3]. Нафион представляет собой полимерный (тефлоновый) каркас с подшитыми к тефлоновой основе концевыми сульфогруппами. Известно, что Тефлон гидрофобен, в то время как сульфогруппы обладают гидрофильными свойствами, т.е. набухший в воде Нафион обладает так называемой амфифильностью [4]; внутри мембраны Нафиона формируется структура типа цилиндрических мицелл с заполненными водой каналами размером 2-3 nm. На границе этих каналов происходит диссоциация концевых сульфогрупп по схеме

$$
\mathrm{R}-\mathrm{SO}_{3} \mathrm{H}+\mathrm{H}_{2} \mathrm{O} \Leftrightarrow \mathrm{R}-\mathrm{SO}_{3}^{-}+\mathrm{H}_{3} \mathrm{O}^{+},
$$

и внутренняя поверхность каналов заряжена отрицательно. Поэтому внутрь каналов эффективно втягиваются катионы [1], что используется для пространственного разделения ионов $\mathrm{H}^{+}$и $\mathrm{OH}^{-}$в установках по водородной энергетике.
В большинстве экспериментальных работ по Нафиону, как правило, исследуется внутренняя структура самого полимера. В то же время в ряде работ были исследованы свойства слоев воды, прилегающей к поверхности полимерной мембраны. Так, в монографии [5] описаны эксперименты, в которых было обнаружено, что при погружении мембраны Нафиона в водную суспензию коллоидных микросфер эти микросферы отталкиваются от мембраны на расстояние порядка нескольких сотен микрон. Область, из которой эффективно выталкиваются коллоидные микросферы, получила название „исключенной зоны“. В то же время известно ([6] и приведенные в этой работе ссылки), что твердотельная подложка может изменять свойства прилегающей к ней воды только в пределах 1-2 монослоев, т. е. на масштабах в несколько нанометров.

Эксперименты, описанные ниже, были в значительной степени мотивированы нашими предыдущими исследованиями по фотолюминесцентной спектроскопии [7-9]. В этих работах было обнаружено, что при набухании полимерной мембраны Нафиона возникает эффект „разматывания“ полимерных волокон в объем воды. Также в этих работах было получено, что размер области, занятой размотанными полимерными волокнами, по- 


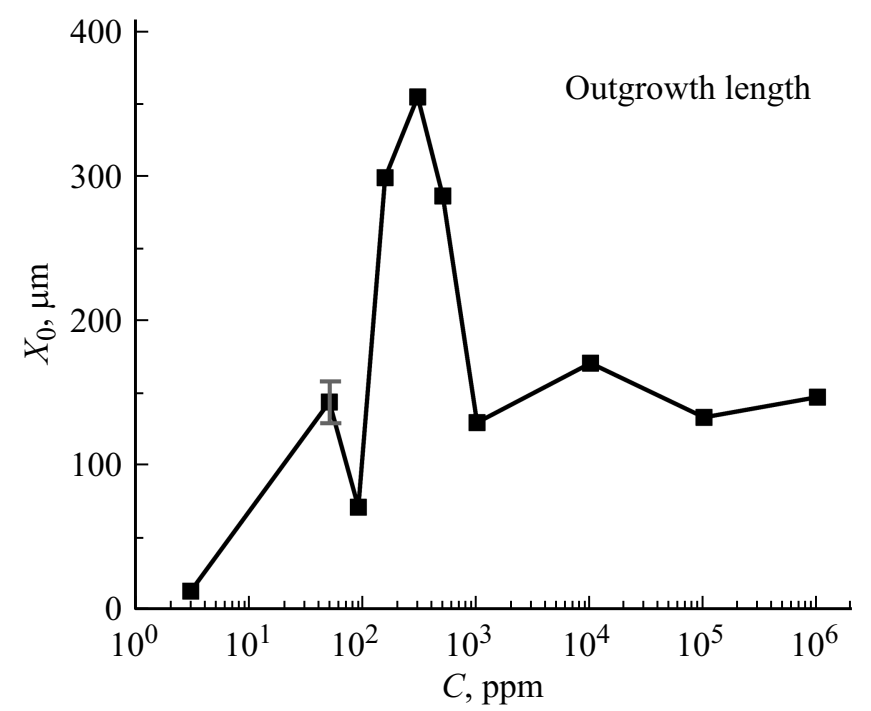

Рис. 1. Изменение размера $X_{0}$ области, заполненной размотанными полимерными волокнами, в зависимости от содержания дейтерия (см. комментарии в работе [8]).

рядка размера исключенной зоны, измеренной в [5]. Поэтому в наших работах [8,9] было высказано предположение, что выталкивание микросфер может быть связано с эффектом разматывания полимерных волокон. Однако, поскольку нам не известен модуль упругости размотанных полимерных волокон, мы не могли сделать соответствующие численные оценки, т.е. вывод о том, что выталкивание микросфер связано именно с эффектом разматывания, не был обоснован. Поскольку приведенные ниже исследования в значительной степени опираются на результаты, полученные в работе [8], в данном разделе имеет смысл более подробно рассказать об этих результатах.

На рис. 1 представлена зависимость, взятая из работы [8] (рис. 9 этой работы). На этом рисунке представлена полуширина $X_{0}$ гауссова распределения $N_{\text {naf }}(x)$ (размер исключенной зоны) в зависимости от содержания дейтерия в воде, в которой происходило набухание полимера. Содержание дейтерия в образцах менялось в результате объемного смешивания тяжелой воды (содержание дейтерия $\left.10^{6} \mathrm{ppm}\right)$, воды, обедненной по дейтерию (deuterium depleted water, DDW, содержание дейтерия $3 \mathrm{ppm}$ ), и обычной природной воды (содержание дейтерия $157 \pm 1$ ppm [10]). Как следует из этого графика, величина $X_{0}$ немонотонно зависит от содержания дейтерия. Самая первая точка на этом графике соответствует обедненной дейтерием воде; мы видим, что эффект „разматывания“ отсутствует для DDW.

В то же время, насколько нам известно, никто до сих пор не изучал динамику набухания Нафиона в кювете, размер которой порядка нескольких сотен микрон, т.е. порядка размера области, занятой размотанными полимерными волокнами в случае кюветы большого размера (чашки Петри, например). Возникает вопрос: что будет, если пластинка Нафиона находится внутри кюветы с жидкостью, и расстояние $L$ между окнами кюветы меньше $X_{0}$ ? В соответствии с данными на рис. 1 эффект разматывания полимерных волокон в обедненной по дейтерию воде не был обнаружен; в этом случае $X_{0} \approx 0$ в пределах погрешности эксперимента, т.е. в этом случае никаких особенностей быть не должно. Но если $L<X_{0}$ (точнее, в данном случае имеет смысл сравнивать масштабы $X_{0}$ и $\left(L-L_{0}\right) / 2$, где $L_{0}-$ толщина пластинки Нафиона, т.е. мы имеем в виду $\left.X_{0}<\left(L-L_{0}\right) / 2\right)$, то следует ожидать, что прорастающие волокна Нафиона будут упираться в окна кюветы, и набухание мембраны будет происходить в других условиях по сравнению с условиями, которые реализуются в кювете, объем которой существенно больше объема полимерной мембраны.

Кроме того, известно, что мембрана Нафиона исходно обладает гидрофобными свойствами, т.е. краевой угол смачивания для капли воды на поверхности мембраны близок к 90․ Однако по мере набухания в воде мембрана становится гидрофильной; в этом случае краевой угол смачивания становится существенно меньше $90^{\circ}$. На рис. 2 приведены фотографии, которые иллюстрируют динамику перехода пластинки Нафиона толщиной $175 \mu \mathrm{m}$ из гидрофобного в гидрофильное состояние. В этом эксперименте на пластинку сухого Нафиона, закрепленную на гладкой горизонтальной подложке, мы наносили каплю воды фиксированного объема (эксперименты проводились с обычной природной водой с содержанием дейтерия $157 \mathrm{ppm}$ ); это соответствует начальному моменту времени. Гидрофобные свойства Нафиона контролировались визуально по изменению угла смачивания. Далее пластинка помещалась в воду

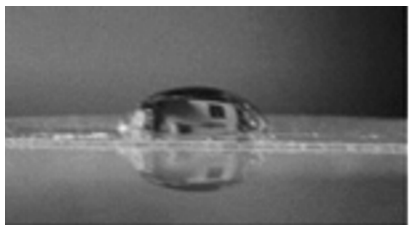

$0 \min$

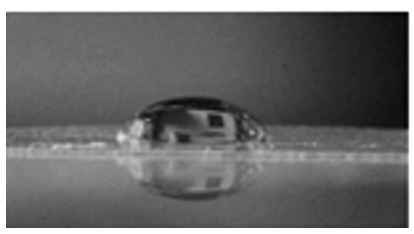

$20 \mathrm{~min}$

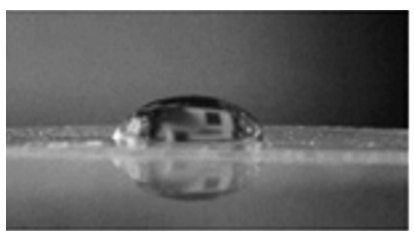

$190 \min$

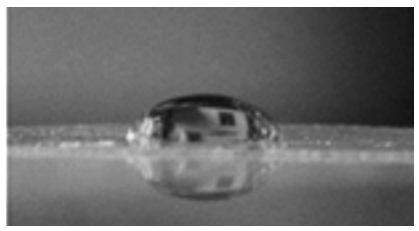

$10 \mathrm{~min}$



$30 \mathrm{~min}$

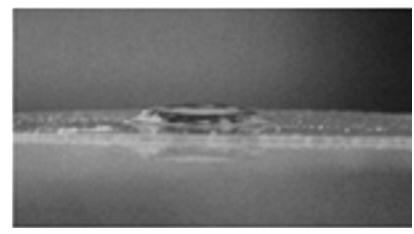

$200 \mathrm{~min}$
Рис. 2. Динамика перехода Нафиона из гидрофобного в гидрофильное состояние. На 200-й минуте происходит резкое изменение краевого угла смачивания. 
в течение $10 \mathrm{~min}$, а затем извлекалась из воды, и на нее вновь наносилась капля. Видно, что угол смачивания не меняется в течение $190 \mathrm{~min}$, т. е. полимер сохраняет гидрофобные свойства, но на двухсотой минуте угол смачивания скачкообразно меняется - Нафион становится гидрофильным.

Согласно результатам работы [8], разматывание полимерных волокон в объем воды происходит практически сразу после погружения полимерной мембраны в воду. Таким образом, проиллюстрированный на рис. 2 переход в гидрофильное состояние наступает в условиях, когда полимерные волокна уже размотаны в объем жидкости. Возникает вопрос, проявляется ли эффект разматывания волокон на переходе в гидрофильное состояние? Поскольку Нафион прозрачен для излучения в ИК диапазоне, но в этом диапазоне поглощают молекулы воды, имеет смысл изучать динамику перехода полимерной мембраны из гидрофобного в гидрофильное состояние с помощью ИК спектроскопии. Настоящая работа посвящена изучению особенностей набухания полимерной мембраны в воде в кювете ограниченного объема в экспериментах по ИК фурье-спектроскопии.

\section{Материалы и методы}

Эксперименты проводились на аналитическом фурьеспектрометре ФСМ 2201 (ООО „Инфраспек“, Россия, Санкт-Петербург). Спектрометр имел следующие характеристики:

- спектральный диапазон от 370 до $7800 \mathrm{~cm}^{-1}$;

- спектральное разрешение во всем диапазоне $1.0 \mathrm{~cm}^{-1}$;

- абсолютная погрешность во всем диапазоне $\pm 0.05 \mathrm{~cm}^{-1}$.

В экспериментах по ИК фурье-спектроскопии был исследован спектральный диапазон 1.8-2.2 этого диапазона обусловлен следующим. Как известно, наиболее сильное поглощение в воде реализуется для полосы валентных колебаний в диапазоне 2.7-3.3 $\mu \mathrm{m}$. Для пластинки Нафиона толщиной $175 \mu \mathrm{m}$ в этом диапазоне коэффициент пропускания близок к нулю. В то же время вблизи $2 \mu \mathrm{m}$ поглощение не такое сильное и обусловлено комбинацией асимметричного валентного и изгибного колебаний молекулы воды [11]. Момент заливки жидкости в кювету соответствовал началу отсчета времени. В экспериментах измерялся коэффициент пропускания кюветы с водой, содержащей пластинку Нафиона. Каждое измерение включало 15 последовательных записей коэффициента пропускания с последующим усреднением и занимало $40 \mathrm{~s}$ (с учетом вычитания фонового поглощения, обусловленного влажностью воздуха). Временной интервал между отдельными измерениями составлял $5 \mathrm{~min}$. Экспериментальный протокол подробно описан в наших недавних работах [12,13], где в экспериментах по ИК фурье-спектроскопии было изучено набухание Нафиона в воде с различным содержанием дейтерия.

В экспериментах использовались пластинки Нафиона N117 (Sigma Aldrich, США) толщиной $L_{0}=175 \mu \mathrm{m}$ и размером $1 \times 1 \mathrm{~cm}$. Пластина помещалась в кювету с окнами из $\mathrm{CaF}_{2}$; этот материал прозрачен для ИК излучения в широком спектральном диапазоне (длинноволновая граница прозрачности соответствует длине волны $\lambda=3 \mu \mathrm{m}$ ). Расстояние $L$ между окнами (толщина кюветы) варьировалось с шагом $10 \mu \mathrm{m}$ в диапазоне $180-220 \mu \mathrm{m}$. Мы исследовали воду, очищенную по технологии Milli-Q, с удельным сопротивлением $18 \mathrm{M} \Omega$ (измерено сразу после получения образца) и содержанием дейтерия $157 \pm 1$ ppm.

Мы также исследовали обедненную дейтерием воду (DDW, Aldrich, США, содержание дейтерия 3 ppm). Наконец, были исследованы растворы $\mathrm{NaCl}$, приготовленные на основе Milli-Q-воды для концентраций в диапазоне $1 \cdot 10^{-14} \mathrm{M}$ и Milli-Q-воды, подвергнутой интенсивному встряхиванию с помощью платформы MultiSpeed Vortex MSV-3500 с частотой $20 \mathrm{~Hz}$ в течение $1 \mathrm{~min}$.

\section{Особенности используемой в экспериментах кюветы}

На рис. $3, a-d$ изображена кювета, заполненная водой. Рисунок $a$ схематично изображает образование полости, свободной от частиц воды, когда кювета заполнена обычной природной водой, и отсутствие этой полости, когда кювета заполнена водой, обедненной по дейтерию (DDW). На рис. $b$ приведена фотография кюветы сразу после заполнения обычной водой; хорошо видна полость, свободная от жидкости. На рис. $c$ мы показываем фотографию кюветы сразу после заполнения обедненной по дейтерию водой; в этом случае полость отсутствует. Для нас было очень важно, чтобы объем жидкости, наливаемой в ячейку, всегда превышал объем самой ячейки, т.е. если мы заливаем жидкость в одно из входных отверстий (помечены на рис. $а$ стрелками, а на рис. $b$ и $c$ окружностями), то вода должна вылиться из другого отверстия. При такой заливке внутри жидкости не образуются пузырьки газа, и весь объем кюветы (за исключением полости) равномерно заполнен водой. Таким образом, полость, образовавшаяся при заливке обычной воды, может возникнуть только вследствие контакта исходно гидрофобных волокон Нафиона и молекул воды. После заполнения входное и выходное отверстия кюветы были закрыты тефлоновыми вставками, но при этом отсутствовала герметичность, т.е. в течение всего эксперимента воздух мог проникать в кювету. Согласно нашей модели (см. ниже), полость образуется в результате контакта между частицами воды и поверхностью мембраны и мгновенного разматывания гидрофобных полимерных волокон в объем жидкости. Поскольку размер $X_{0}$ области, которая занята размотанными полимерными волокнами в кювете, много меньше расстояния $L$ между окнами кюветы, следует ожидать, 


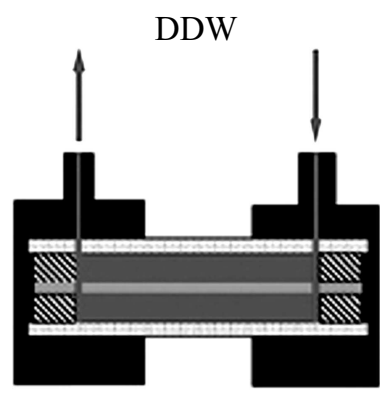

Water Spacer
Ordinary water

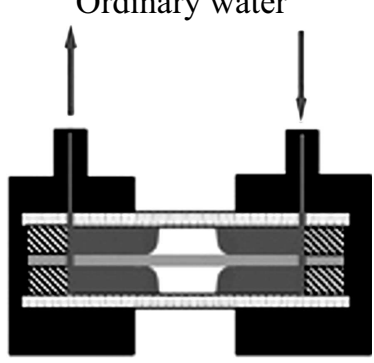

Window

Nafion plate

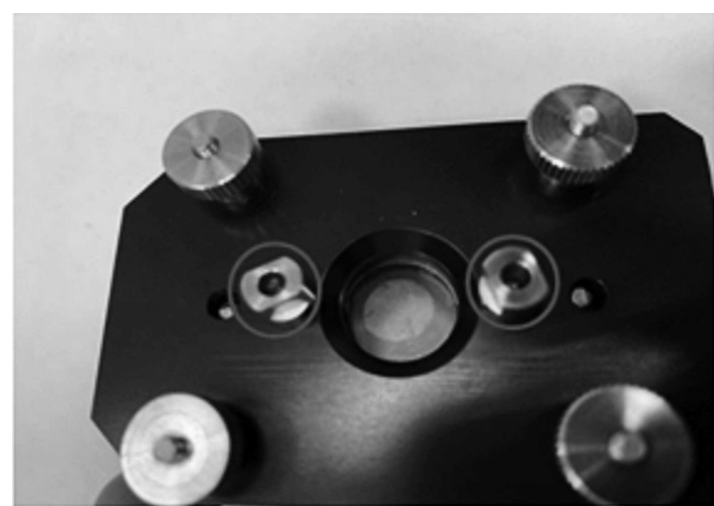

$c$
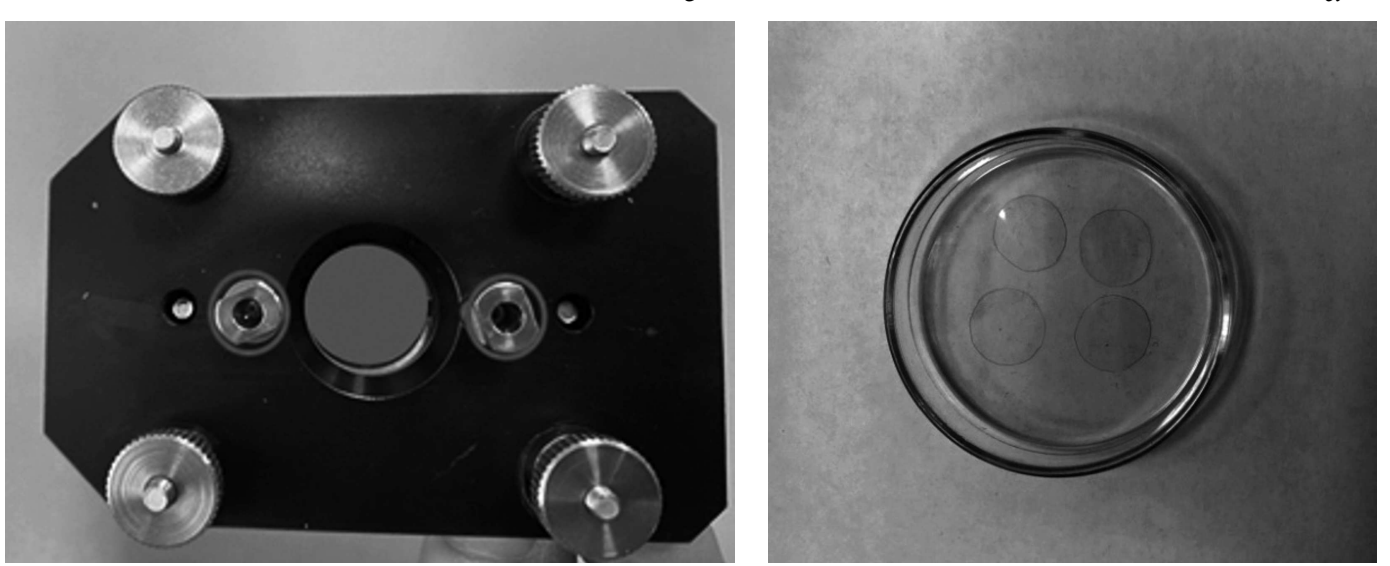

Рис. 3. Ячейка, используемая в экспериментах по ИК фурье-спектроскопии. ( $a$ ) Схематическое изображение кюветы, заполненной водой, обедненной по дейтерию, и обычной водой. Стрелками указаны входное и выходное отверстия, через которые кювета заполнялась жидкостью; жидкость заливалась через входное отверстие, в то время как избыток жидкости выливался через выходное отверстие. $(b)$ Фотография ячейки сразу после заполнения обычной водой; входное/выходное отверстия выделены окружностями $(\mathrm{DDW}) .(c)$ Фотография ячейки сразу после заполнения водой, обедненной по дейтерию. (d) Фотография пластинок Нафиона.

что полимерные волокна будут с силой упираться в окна кюветы. Это приведет к возникновению поля локальных сдвиговых напряжений и „выдавливанию“ молекул воды, оказавшихся между гидрофобными волокнами. В то же время периферийные области пластинки Нафиона (рис. 3,a) всегда находятся в контакте с водой, и полимер в периферийных областях продолжает набухать, несмотря на наличие полости. Таким образом, из-за контакта с водой в периферийных областях размотанные волокна утрачивают гидрофобные свойства, и полость в конечном итоге схлопывается. Ясно, что скорость схлопывания должна зависеть от площади контакта между водой и периферийными областями пластины Нафиона. Поэтому мы стремились к тому, чтобы пластинки Нафиона имели одинаковую форму и размер; на рис. $3, d$ представлены образцы пластинок Нафиона, использованных в этом эксперименте. Кроме того, поскольку качество полировки окон является неконтролируемым параметром, кювета собиралась таким образом, чтобы поверхности окон, контактирующие с жидкостью, были каждый раз одинаковыми.

Отсутствие полости в случае DDW в отличие от обычной воды можно объяснить в рамках подхода, предложенного в [8,9], см. также рис. 1, где показано, что для DDW (самая первая точка на графике) отсутствует эффект разматывания полимерных волокон в объем жидкости. Поскольку для обычной воды размер $X_{0}$ области, занятой полимерными волокнами, порядка $300 \mu \mathrm{m}$, толщина пластины Нафиона составляет $L_{0}=175 \mu \mathrm{m}$ (на рис. 3 представлены фотографии для кюветы с расстоянием между окнами $L=200 \mu \mathrm{m}$ ), получаем, что для обычной воды размер области, которую могут занимать размотанные полимерные волокна, составляет с каждой стороны пластинки Нафиона величину $\left(L-L_{0}\right) / 2 \approx 12 \mu \mathrm{m}$. Поэтому в случае обычной воды размотанные полимерные волокна упираются в окна кюветы. В этом случае можно говорить о создании поля локальных сдвиговых напряжений, что приводит к „усилению“ гидрофобного эффекта: из-за локальных 




Рис. 4. Спектр пропускания для воды в диапазоне $1.8<\lambda<2.2 \mu \mathrm{m}$. Расстояние между окнами $L=180 \mu \mathrm{m}$.

напряжений, возникающих при контакте полимерных волокон с поверхностью окна кюветы, молекулы воды наиболее эффективно выталкиваются из промежутков между гидрофобными волокнами, что приводит к формированию полости. В этом случае проявляются микрореологические свойства полимерных волокон в воде; более подробно о микрореологических свойствах мягкой материи см. монографию [14].

\section{Экпериментальные результаты}

В экспериментах измерялась величина коэффициента пропускания $K=I / I_{0}$, где $I$ и $I_{0}-$ интенсивности прошедшего и падающего излучения, которые по закону Ламберта-Бугера-Бера [15] связаны соотношением $I=I_{0} \exp (-\kappa L)$, где $\kappa-$ коэффициент экстинкции, $L-$ расстояние между окнами кюветы. На рис. 4 приведен типичный пример спектра пропускания для обычной воды (содержание дейтерия 157 ppm), залитой в кювету с расстоянием между окнами $L=180 \mu \mathrm{m}$ в диапазоне $1.8<\lambda 2.2 \mu \mathrm{m}$; при этом спектральный минимум $K_{\min }$ реализуется при $\lambda=1.93 \mu \mathrm{m}$. Было замечено, что при малых временах набухания $t$ и малых расстояниях $L$ коэффциент пропускания $K(\lambda=1.8 \mu \mathrm{m}) \approx 0.7$ для всех спектрограмм, но с ростом $t$ и $L$ величина $K(\lambda=1.8 \mu \mathrm{m})$ слегка уменьшается, в то время как $K(\lambda=2.2 \mu \mathrm{m})$ уменьшается сильнее. Уменьшение величины $K$ на краях исследуемой полосы связано с аддитивным вкладом более интенсивной полосы поглощения, центрированной вблизи $\lambda=3 \mu \mathrm{m}$; эта полоса обусловлена валентными колебаниями молекул воды [11]. Поскольку в дальнейшем нас будет интересовать именно величина $\left|\ln K_{\min }\right|$ на длине волны $\lambda=1.93 \mu \mathrm{m}$, имеет смысл отсчитывать величину $K_{\min }$ от общего для всех спектрограмм уровня. Действительно, при $K_{\min }<1$ логарифм быстро убывает, и неточности в определении $K_{\min }$ могут приводить к существенным ошибкам $\left|\ln K_{\min }\right|$. Поэтому для всех приведенных ниже спектрограмм $K(\lambda=1.8 \mu \mathrm{m})=0.7$.

На рис. 5 приведены результаты измерений величины $\left|\ln K_{\min }\right|$ для воды в кювете в зависимости от расстояния между флюоритовыми окнами: $L=180,190$, 200, 210 и $220 \mu \mathrm{m}$. Экспериментальные зависимости являются результатом усреднения по пяти последовательным измерениям. Выбор минимального значения $L=180 \mu \mathrm{m}$ обусловлен тем, что толщина пластинки Нафиона $\mathrm{N} 117 L_{0}=175 \mu \mathrm{m} \approx 180 \mu \mathrm{m}$. Выбор максимального значения $L=220 \mu \mathrm{m}$ обусловлен тем, что в этом случае интенсивность $I$ прошедшего излучения фактически выходит на нулевой уровень, т.е. результаты измерений становятся некорректными. Полученная для воды зависимость $\left|\ln K_{\min }\right|(L)$ аппроксимируется функцией $Y=0.027+0.019 X$, т. е. получаем для коэффициента экстинкции $\kappa \approx 0.019 \mu \mathrm{m}^{-1}$. Также была измерена величина $\left|\ln K_{\min }\right|$ для сухого (безводного) Нафиона. В этом случае поглощение на длине волны $\lambda=1.93 \mu \mathrm{m}$ обусловлено водой, инкапсулированной внутри нанометровых замкнутых полостей сухого Нафиона [1], т.е. $\left|\ln K_{\min }\right|=\kappa\left(C_{w}\right)_{0} L_{0}$, где $\left(C_{w}\right)_{0}-$ концентрация воды внутри сухого Нафиона. Имеем оценку $\left(C_{w}\right)_{0}=0.174$.

Нами были сняты спектры пропускания для Нафиона, который вымачивался в различных жидкостях, с интервалом $5 \mathrm{~min}$. На рис. 6 приведены типичные спектры пропускания $K$, снятые с интервалом $5 \mathrm{~min}$ на временном интервале $70<t<100 \mathrm{~min}$ в обычной воде в кювете с расстоянием между окнами $L=200 \mu \mathrm{m}$. Видно, что коэффициент пропускания $K$ плавно уменышается по мере набухания.

На рис. 7 приведены зависимости коэффициента пропускания для воды, обедненной дейтерием (содержание дейтерия 3 ppm), в кювете с расстоянием между окнами $L=200 \mu \mathrm{m}$ на интервале $0<t<25 \mathrm{~min}$. Здесь $t=0$ соответствует времени заливки жидкого образца в кювету

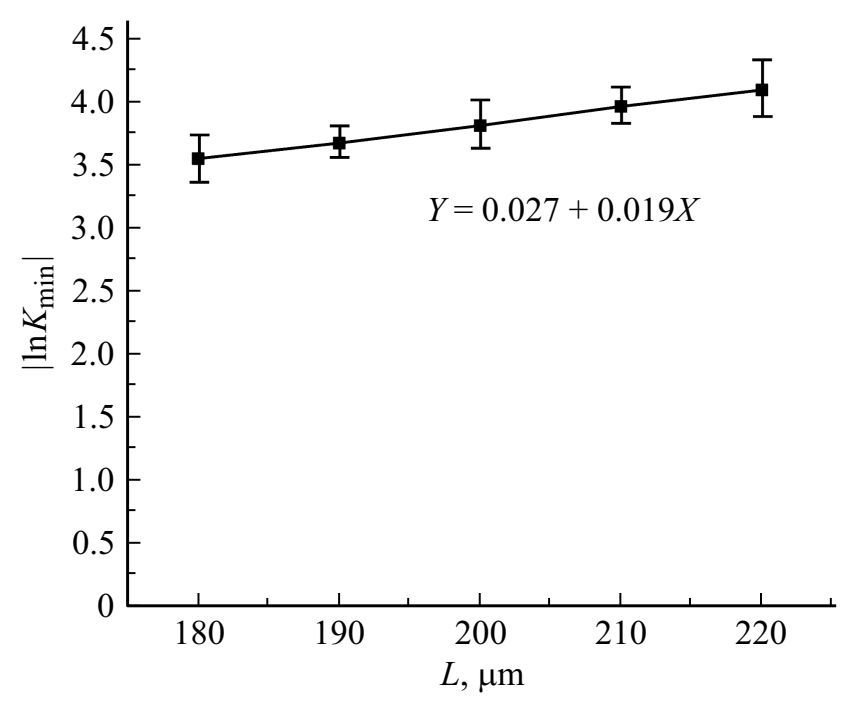

Рис. 5. Зависимости $\left|\ln K_{\min }\right|$ для воды в зависимости от расстояния $L$ между окнами кюветы. 


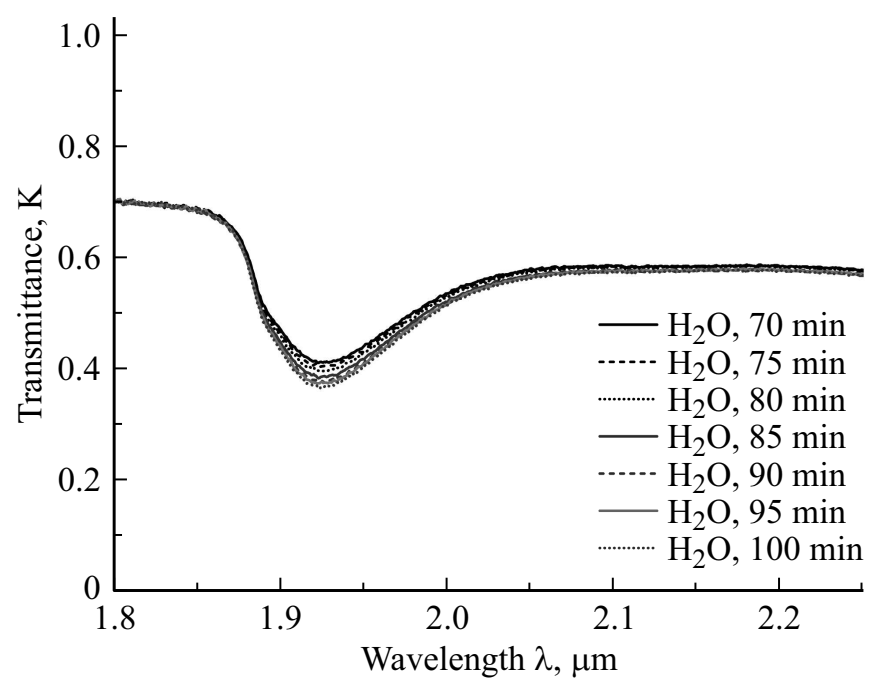

Рис. 6. Спектры коэффициента пропускания $K$ в диапазоне $1.8<\lambda<2.2 \mu$ m при вымачивании пластинки Нафиона в обычной воде (содержание дейтерия $157 \mathrm{ppm}$ ); расстояние между окнами кюветы $L=200 \mu \mathrm{m}$, интервал времен вымачивания $70<t<100 \mathrm{~min}$.

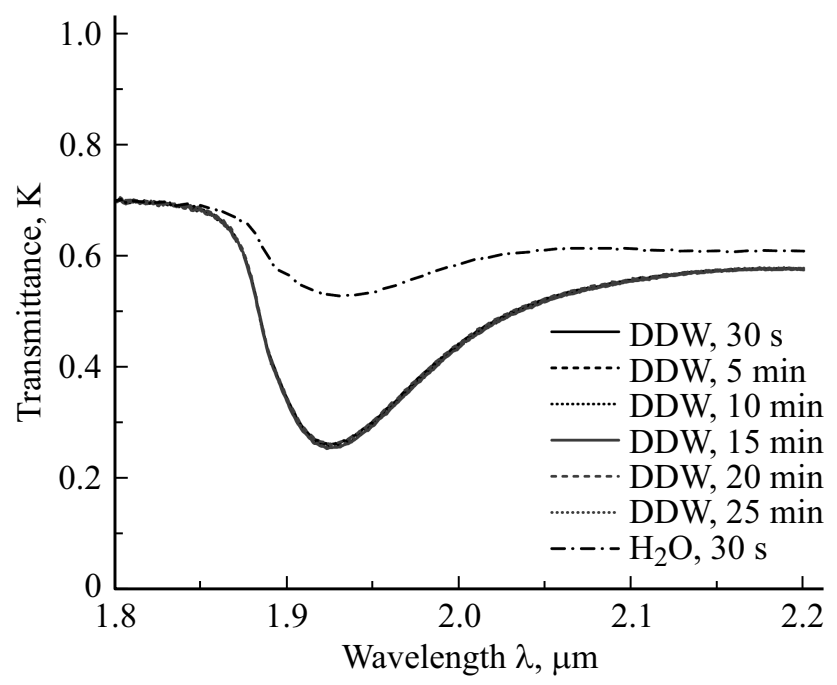

Pис. 7. Спектры коэффициента пропускания в диапазоне $1.8<\lambda<2.2 \mu$ m при помещении пластинки Нафиона в кювету с обедненной по дейтерию водой; расстояние между окнами $L=200 \mu \mathrm{m}$, интервал времен вымачивания $30 \mathrm{~s}<t<25 \mathrm{~min}$. Верхняя кривая - спектр коэффициента пропускания обычной воды при времени вымачивания $t=30 \mathrm{~s}$.

и времени снятии самого первого измерения, которое занимает примерно $15 \mathrm{~s}$, т. е. самая первая точка на этом графике соответствует моменту времени $t \approx 30 \mathrm{~s}$. Видно, что спектры практически одинаковы для всех $t$; возникает впечатление, что изображен только один график. Здесь же мы приводим спектр пропускания для обычной воды, снятый в момент времени $t \approx 30 \mathrm{~s}$. Видно, что этот спектр существенно отличается от соответствующих спектров для воды, обедненной дейтерием. Отметим, что в нашей работе [13] были изучены спектры пропускания воды в диапазоне $1.8-2.2 \mu \mathrm{m}$ в зависимости от содержания $C$ дейтерия и было получено, что коэффициент пропускания одинаков в диапазоне $1<C<10^{4} \mathrm{ppm}$, т.е. обнаруженный эффект не может быть связан с различными поглощательными характеристиками обычной и обедненной по дейтерию воды. Мы связываем различие спектров на рис. 6 с отсутствием разматывания полимерных волокон в обедненной по дейтерию воде и соответственно с отсутствием в этой воде полости.

На основании полученных спектров можно оценить усредненную по длине кюветы $L$ концентрацию воды $\left\langle C_{w}\right\rangle$. Переписав закон Бугера в виде

$I(t)=I_{0} \exp \left(-\kappa \int_{0}^{L} C_{w}(t, x) d x\right) \approx I_{0} \exp \left(=\kappa\left\langle C_{w}(t)\right\rangle L\right)$,

получаем

$$
\left\langle C_{w}(t)\right\rangle=\frac{\left|\ln K_{\min }(t)\right|}{\kappa L} .
$$

В этой формуле учтена зависимость $\left\langle C_{w}\right\rangle$ от времени вымачивания $t$ как от параметра. На рис. 8 приведены зависимости $\left\langle C_{w}(t)\right\rangle$ от времени вымачивания $t$ для кювет с расстоянием между окнами $L=180,190,200,210$ и $220 \mu \mathrm{m}$. Штриховая линия соответствует концентрации воды в сухом Нафионе $\left(C_{w}\right)_{0}=0.174$ (базовая линия).

Рассмотрим (для определенности) зависимость $\left\langle C_{w}(t)\right\rangle$ для $L=180 \mu \mathrm{m}$. Видно, что концентрация воды испытывает резкий скачок примерно через $10 \mathrm{~min}$ набухания, что сопровождается схлопыванием полости, изображенной на рис. 3. Будем называть такое резкое изменение „первым скачком“. Далее, примерно на $90 \mathrm{~min}$ набухания происходит еще один скачок, который не связан со схлопыванием полости (выделено контуром синего цвета); будем называть это „вторым скачком“. Отметим, что вторые скачки, только с меньшей амплитудой, наблюдаются и для $L=190,210$ и $220 \mu \mathrm{m}$ (выделены соответствующими контурами).

Как показали наши измерения, первый скачок связан со схлопыванием полости; при этом вся поверхность полимера покрыта жидкостью, что соответствует обычному режиму набухания. Таким образом, второй скачок может быть связан только с достаточно резким увеличением концентрации воды в объеме самой мембраны. Для проверки этой гипотезы мы изучали временной ход

$$
\left\langle C_{w}(t)\right\rangle_{0}=\frac{\left|\ln K_{\min }(t)\right|}{\kappa L_{0}}
$$

- концентрации воды в объеме мембраны при ее высыхании; здесь $L_{0}=175 \mu \mathrm{m}$ - толщина пластинки Нафиона. В этом эксперименте мембрана Нафиона вымачивалась в кювете с расстоянием между окнами $L=180 \mu \mathrm{m} \mathrm{в} \mathrm{течение} t_{1}=80$ и $t_{2}=110 \mathrm{~min}$, т.е. до и после наступления второго скачка. Затем мы вынимали мембрану из кюветы, и она высыхала на воздухе при комнатной температуре (рис. 9). Зависимости концентрации воды $\left\langle C_{w}(t)\right\rangle_{0}$ от времени высыхания для времен 
набухания $t_{1}$ и $t_{2}$ различны. Это косвенно подтверждает гипотезу о том, что скачок зависимости $\left\langle C_{w}(t)\right\rangle$ на рис. 8 на интервале $t_{1}<t<t_{2}$ связан со структурными изменениями в объеме мембраны, которые сопровождаются резким увеличением содержания воды. Отметим, что структурные фазовые переходы, которые происходят внутри полимерной матрицы при набухании в воде и сопровождаются резким ростом содержания воды в объеме мембраны, описаны в работе [16].

Обратимся вновь к рис. 2, где проиллюстрирован переход Нафиона из гидрофобного в гидрофильное состояние при вымачивании пластинки Нафиона N117 (толщина пластинки $175 \mu \mathrm{m}$ ) в обычной природной воде (содержание дейтерия 157 ppm) в кювете неограниченного объема (чашка Петри). Очевидно, что при таком вымачивании происходит прорастание полимерных волокон в объем воды на расстояние $X_{0} \approx 300 \mu \mathrm{m}$ (рис. 1). В этом случае переход в гидрофильное состояние завершается на временах $190<t<200 \mathrm{~min}$. Очевидно, что для пластинки Нафиона N117, которая набухает в обычной воде в кювете с расстоянием между окнами $L=180 \mu \mathrm{m}$, эффект прорастания подавлен за счет геометрического фактора. На наш взгляд, в этом случае переход в гидрофильное состояние происходит гораздо раньше, чем при набухании в чашке Петри. В пользу этой гипотезы также свидетельствуют зависимости $\left\langle C_{w}(t)\right\rangle$ для кювет с толщинами $L=190,210$ и $220 \mu \mathrm{m}$. Для этих кювет второй скачок также наступает гораздо раньше, чем наступает переход в гидрофильное состояние при набухании полимерной мембраны в чашке Петри (рис. 2). Таким образом, можно сделать вывод, что эффект прорастания полимерных волокон влияет на кинетику набухания мембраны: чем слабее этот эффект выражен, тем быстрее наступает переход в гидрофильное состояние.

Исследования в этом направлении продолжаются, и данный вывод в дальнейшем будет уточнен.

Как следует из графиков на рис. 8, на кинетику перехода в гидрофильное состояние влияет также изотопный состав воды, в которой набухает мембрана. Как следует из хода зависимости $\left\langle C_{w}(t)\right\rangle$ для обедненной по дейтерию воды (расстояние между окнами кюветы $L=200 \mu \mathrm{m})$, никаких особенностей в виде первого и второго скачка нет. Как уже отмечалось, полость, изображенная на рис. 3 , для обедненной по дейтерию воды не формируется; также отсутствует скачок, связанный, по нашей гипотезе, со структурными изменениями в объеме мембраны. Более детальному изучению динамики набухания в воде с разным изотопным составом (в частности, изучению появления второго скачка) будет посвящена отдельная работа.

Обратим внимание на еще одну интересную особенность, которая проявляется при набухании пластинки Нафиона N117 толщиной $L_{0}=175 \mu \mathrm{m}$ в обычной воде (содержание дейтерия $157 \pm 1 \mathrm{ppm}$ ) в кювете с расстоянием между окнами $L=200 \mu \mathrm{m}$ (рис. 8). В этом случае полость, свободная от частиц воды, возникает

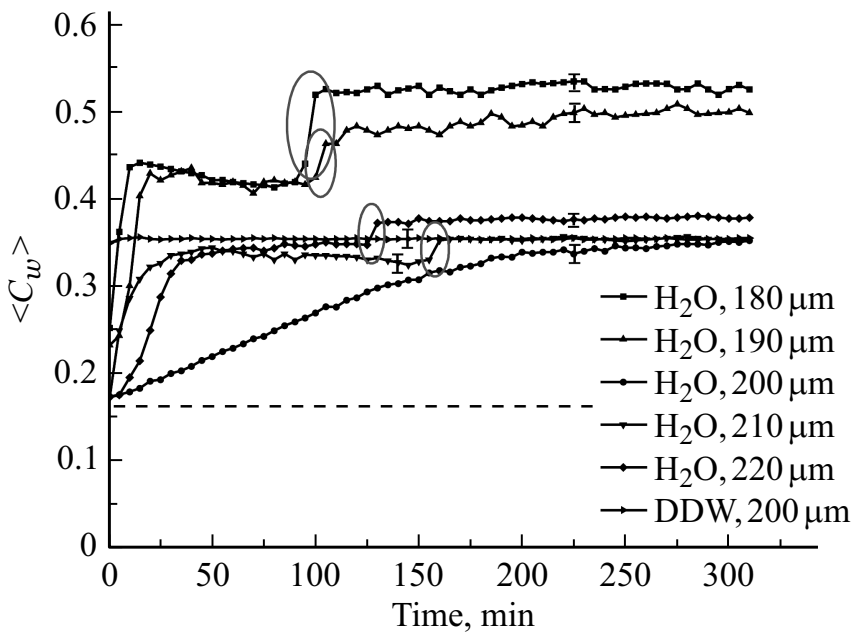

Рис. 8. Зависимость средней концентрации воды $\left\langle C_{w}(t)\right\rangle$ при $180 \leq L \leq 220 \mu \mathrm{m}$ для обычной воды (содержание дейтерия 157 ppm). Эллипсами помечены „вторые скачки“. Также приведен график для вымачивания Нафиона в обедненной по дейтерию воде (содержание дейтерия 1 ppm). Штриховая линия соответствует концентрации воды $C_{w 0}=0.174$ для сухого Нафиона.

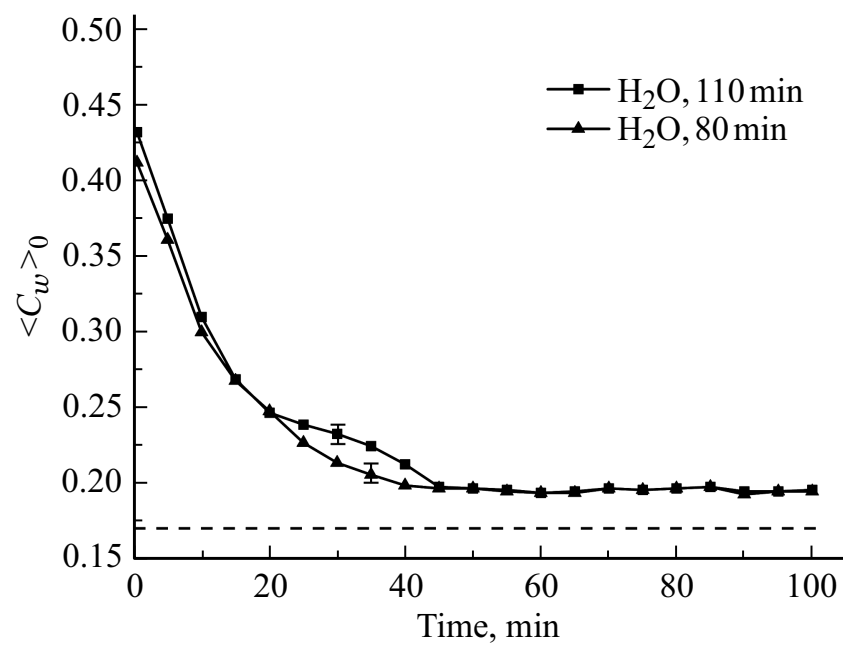

Рис. 9. Зависимость средней концентрации воды $\left\langle C_{w}(t)\right\rangle_{0}$ от времени $t$ высыхания Нафиона после вымачивания в кювете с расстоянием между окнами $L=180 \mu \mathrm{m} \mathrm{в} \mathrm{течение} 80$ и $110 \mathrm{~min}$. Штриховая линия соответствует концентрации воды $C_{w 0}=0.174$ для сухого Нафиона.

и не исчезает вплоть до времен $t \sim 200 \mathrm{~min}$. Возникает вопрос, почему схлопывание полости в кювете с расстоянием между окнами $L=200 \mu \mathrm{m}$ происходит столь медленно? Размотанные в объем воды волокна Нафиона могут занять область размером $(200-175) / 2 \approx 12 \mu \mathrm{m}$ с обеих сторон пластинки Нафиона; в этом случае полость почему-то схлопывается аномально медленно. Нам, однако, не известно, чем выделен этот размер для полимерных волокон Нафиона. 


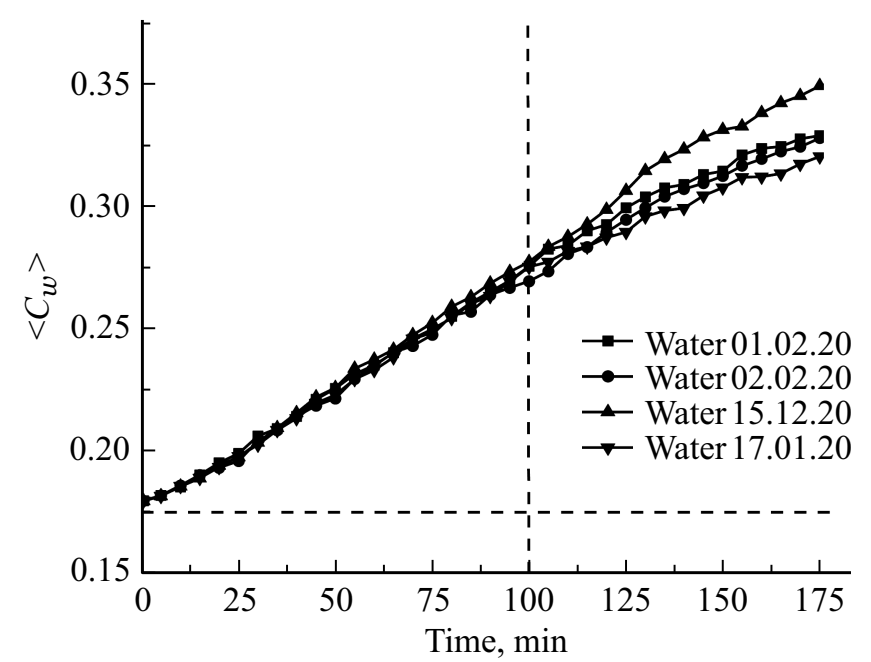

Рис. 10. Зависимость средней концентрации воды $\left\langle C_{w}(t)\right\rangle$ при $L=200 \mu$ m для обычной воды, полученной в разные дни на различных Milli-Q-установках. Штриховая линия соответствует концентрации воды $C_{w 0}=0.174$ для сухого Нафиона.

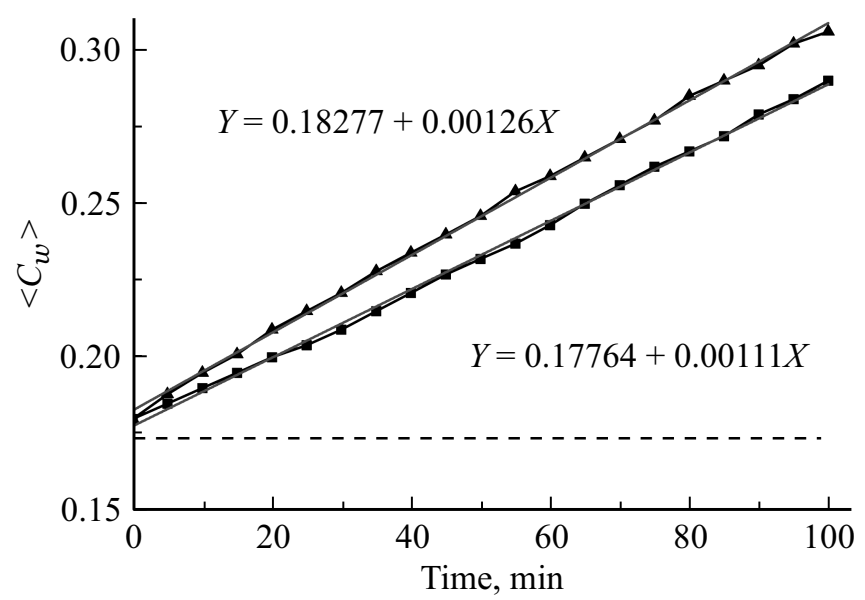

Рис. 11. Зависимости средней концентрации воды $\left\langle C_{w}(t)\right\rangle_{\text {для }}$ обычной воды, полученные в двух различных кюветах с расстоянием между окнами $L=200 \mu \mathrm{m}$. Штриховая линия соответствует концентрации воды $C_{w 0}=0.174$ для сухого Нафиона.

Рассмотрим случай $L=200 \mu \mathrm{m}$ более подробно. На рис. 10 приведены зависимости $\left\langle C_{w}(t)\right\rangle$ в кювете, окна которой были ориентированы таким образом, что поверхности „жидкий образец- $\mathrm{CaF}_{2}$ “ были фиксированными. Полученные графики соответствуют образцам, полученные на разных установках Milli-Q в разные дни. Как следует из графиков, в пределах первых $100 \mathrm{~min}$ нет смысла рассчитывать экспериментальные погрешности: в течение этого времени точки на графиках фактически совпадают, и только на временах $t>100 \mathrm{~min}$ разброс между крайними точками превышает $1 \%$ по концентрации $\left\langle C_{w}(t)\right\rangle$. Именно поэтому на рис. 8 приведены погрешности для времени $t>100 \mathrm{~min}$; эти погрешности рассчитаны по результатам пяти последовательных измерений.

Поскольку волокна Нафиона упираются в поверхность окна, динамика схлопывания изображенной на рис. 3 полости может контролироваться взаимодействием между размотанными волокнами и поверхностью окна; повидимому, в данном случае можно говорить о специфической силе трения. На рис. 11 приведены типичные примеры зависимостей $\left\langle C_{w}(t)\right\rangle$ для двух различных кювет. Видно, что прямолинейная зависимость в пределах первых $100 \mathrm{~min}$ набухания сохраняется, но для одной прямой коэффициент наклона $k=0.00126$, а для другой $k=0.00111$.

Оказалось, что динамика схлопывания полости, образованной гидрофобными полимерными волокнами, контролируется не только качеством поверхности окон кюветы, но зависит также от ионного состава и от предварительной обработки жидких образцов. Так, на рис. 12 приведено семейство зависимостей $\left\langle C_{w}(t)\right\rangle$ для водного раствора $\mathrm{NaCl}$, концентрация которого варьировала в диапазоне $10^{-14}-1 \mathrm{M}$. Исследования водных ионных растворов были мотивированы результатами [17-19], где было показано, что при ионных добавках возрастает объемная плотность нанопузырьков. Для соли $\mathrm{NaCl}$ концентрация $10^{-14} \mathrm{M}$ является выделенной: при такой концентрации подвижность определенного класса инфузорий имеет глубокий минимум, приближающийся почти к нулю [20]. Чтобы не загромождать рисунок, приведены данные для концентраций $1,10^{-4}, 10^{-6}$ и $10^{-14} \mathrm{M}$; тамже приведена зависимость для воды. На этом же рисунке приведены оценки размера $X_{0}$ области, занятой полимерными волокнами при их разматывании в кювету,

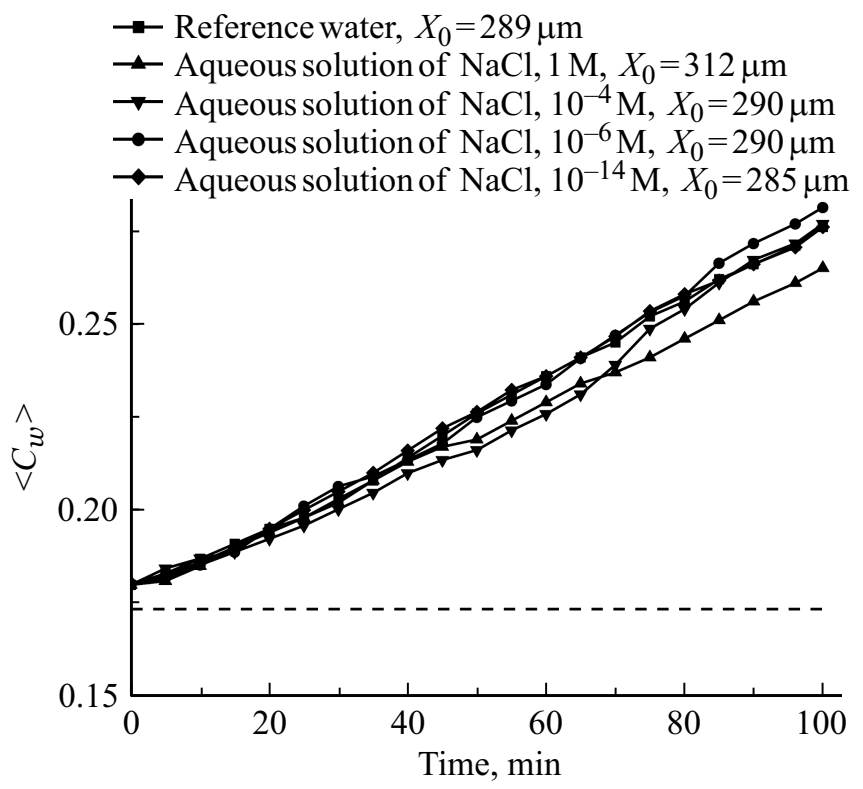

Рис. 12. Зависимости $\left\langle C_{w}(t)\right\rangle$ для водного раствора $\mathrm{NaCl}$ с концентрациями $1,10^{-4}, 10^{-6}$ и $10^{-14} \mathrm{M}$ при $L=200 \mu \mathrm{m}$. Также приведены оценки $X_{0}$. Штриховая линия соответствует концентрации воды $C_{w 0}=0.174$ для сухого Нафиона. 


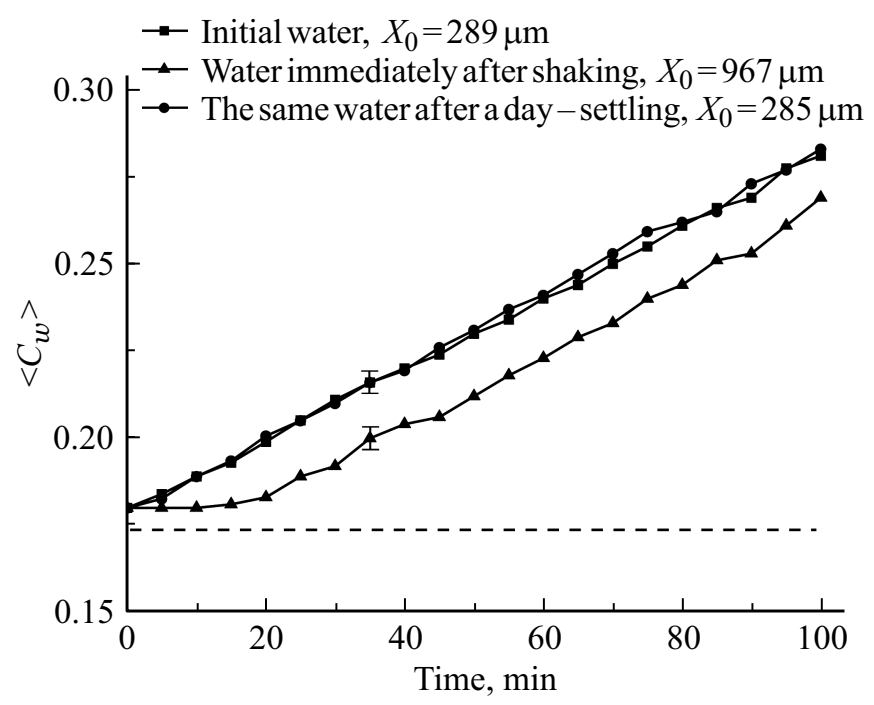

Рис. 13. Зависимости $\left\langle C_{w}(t)\right\rangle$ для исходной воды, воды, подвергнутой встряхиванию на виброплатформе, и воды, отстоявшейся в течение суток после встряхивания при $L=200 \mu \mathrm{m}$. Также приведены оценки $X_{0}$. Штриховая линия соответствует концентрации воды $C_{w 0}=0.174$ для сухого Нафиона.

объем которой существенно превышает объем пластинки Нафиона. Для этого были проведены эксперименты по фотолюминесцентной спектроскопии, описанные в работе [8]. Как следует из приведенных зависимостей, размер $X_{0}$ увеличивается с ростом концентрации ионов, но при концентрации $\leq 10^{-4} \mathrm{M}$ величина $X_{0}$ в пределах экспериментальной погрешности выходит на уровень воды. В то же время ход зависимостей $\left\langle C_{w}(t)\right\rangle$ отличается от прямолинейного вплоть до концентрации $10^{-14} \mathrm{M}$; только для этой концентрации зависимость прямолинейна во всей области $0<t<100 \min$ и практически совпадает с зависимостью для воды. Таким образом, отклонения от прямолинейной зависимости могут быть связаны с привнесением в воду внешних ионных примесей.

Наконец, нами были изучены образцы воды, подвергнутой интенсивному встряхиванию на виброплатформе Vortex MSV-3500 на частоте $20 \mathrm{~Hz}$ в течение $1 \mathrm{~min}$. Эти исследования были мотивированы результатами работ [21,22], где было показано, что встряхивание приводит к росту объемной плотности нанопузырьков примерно в 10 раз. Однако после встряхивания и отстаивания в течение определенного времени исходные свойства должны восстановиться. На рис. 13 приведена временная зависимость $\left\langle C_{w}(t)\right\rangle$ до и сразу после встряхивания, а также спустя сутки после встряхивания; кроме того, приведены оценки размера $X_{0}$ для исследованных жидкостей. Сразу после встряхивания и в течение первых $15 \mathrm{~min}$ наблюдается замедление роста $\left\langle C_{w}(t)\right\rangle$ по сравнению с исходной водой. Также возрастает размер $X_{0}$. Однако спустя сутки жидкость возвращается в свое исходное состояние. Таким образом, наличие нанопузырьков, изотопный состав и растворен- ные ионы влияют на гидрофобные свойства полимерных волокон, образующих полость на рис. 3.

\section{Обсуждение результатов}

Как уже отмечалось, особенности временной динамики изображенной на рис. 3 полости мы связываем с эффектом прорастания полимерных волокон в объем воды. Этот вывод основан на отсутствии этой полости в воде, облегченной дейтерием, для которой эффект прорастания отсутствует. Если расстояние $L$ между окнами кюветы меньше размера $X_{0}$ области, внутрь которой прорастают полимерные волокна в случае „неограниченного“ размера кюветы (например, чашка Петри), то проросшие в объем воды полимерные волокна неизбежно упираются в окна кюветы. Это должно привести к возникновению поля механических напряжений и связанных с ними деформаций, т.е. в данном случае проявляются микрореологические свойства [14] набухающей мембраны. Важно, что эти напряжения возникают в системе „скрученных“ полимерных волокон, которые исходно обладают гидрофобными свойствами, т.е. положение молекулы воды, оказавшейся в промежутках между такими волокнами, будет неустойчивым.

Следует ожидать, что на динамику формирования и схлопывания полости должны влиять нанопузырьки растворенного газа. Действительно, исследуемые жидкие образцы не были дегазированы. При разматывании полимерных волокон на поверхности гидрофобной мембраны возникают выступы и неровности, которые играют роль центров нуклеации поверхностных нанопузырьков [23]. Эти нанопузырьки „выносятся“ прорастающими волокнами в сторону окна кюветы, и в поле возникающих механических напряжений может происходить коалесценция (схлопывание) нанопузырьков, что должно вносить вклад в формирование полости. Это косвенно подтверждается результатами, полученными с водными растворами $\mathrm{NaCl}$, а также с образцами, подвергнутыми встряхиванию.

Действительно, как показано в $[21,22]$, в водных растворах солей в объеме жидкости возникают стабилизированные ионами газовые нанопузырьки с радиусом порядка $200 \mathrm{~nm}$. Объемная плотность стабилизированных ионами газовых нанопузырьков в деионизованной воде (наличие ионной компоненты в этом случае обусловлено собственной диссоциацией молекул воды) $n \sim 10^{6} \mathrm{~cm}^{-3}$, т. е. между поверхностью мембраны площадью $\sim 1 \mathrm{~cm}^{2}$ и окном кюветы находится $\sim 10^{3}$ нанопузырьков. Таким образом, механизм, связанный с присутствием нанопузырьков, не может быть ключевым для формирования полости, поскольку нанопузырьков слишком мало. В то же время незначительное замедление схлопывания полости (рис. 12 и 13) может быть связано именно с повышением объемной плотности нанопузырьков.

Таким образом, основной механизм формирования полости - это именно исходно гидрофобные свойства 
полимерных волокон. Поскольку пластинка Нафиона в периферийных областях контактирует с водой (рис. 3), размотанные полимерные волокна с течением времени приобретают гидрофильные свойства, и полость в конце концов схлопывается.

\section{Заключение}

В настоящей работе было впервые получено, что при набухании Нафиона в обычной природной воде (содержание дейтерия $157 \mathrm{ppm}$ ) в кювете ограниченного объема между поверхностью мембраны и окном кюветы практически мгновенно возникает полость, свободная от молекул воды. В то же время в случае набухания в воде, свободной от дейтерия, эта полость не образуется. Поскольку для воды, обедненной по дейтерию, отсутствует эффект разматывания полимерных волокон, был сделан вывод, что формирование полости также обусловлено разматыванием волокон. Поскольку полимерные волокна обладают исходно гидрофобными свойствами, и эти волокна с усилием упираются в окна кюветы, молекулы воды, заключенные между напряженными гидрофобными волокнами, эффективно выталкивается, что и приводит к формированию полости.

Таким образом, новизна работы заключается, вопервых, в обнаружении нового механизма взаимодействия полимерных волокон и молекул воды при механических напряжениях гидрофобных волокон. Было замечено, что образовавшаяся полость со временем схлопывается, т.е. мембрана Нафиона в конце концов полностью покрывается слоем жидкости, и набухание полимера происходит в условиях, близких к условиям набухания в чашке Петри. Как известно, в процессе набухания исходно гидрофобный Нафион переходит в гидрофильное состояние, что сопровождается скачкообразным уменьшением угла смачивания. В эксперименте была изучена динамика схлопывания полости и режимы набухания Нафиона в кюветах с различным расстоянием между окнами. Поскольку Нафион прозрачен для излучения в ИК диапазоне, но в этом диапазоне поглощают молекулы воды, эти режимы были изучены в эксперименте по ИК фурье-спектроскопии: усредненная по длине кюветы концентрация воды $\langle C(t)\rangle$ вдоль трассы ИК излучения резко меняется при схлопывании полости и переходе Нафиона в гидрофильное состояние. Таким образом, в зависимости $\langle C(t)\rangle$ возникают два резких скачка: первый скачок соответствует схлопыванию полости, а второй скачок - переходу в гидрофильное состояние. Естественно предположить, что размотанные в объем воды полимерные волокна препятствуют проникновению воды внутрь мембраны, т.е. в условиях размотанных полимерных волокон набухание полимера происходит медленнее, чем в отсутствие разматывания. Именно это и было получено в эксперименте: оказалось, что чем меньше толщина слоя, занятого размотанными полимерными волокнами, тем быстрее происходит пе- реход из гидрофобного в гидрофильное состояние, т.е. второй скачок наступает раньше. При этом для всех рассмотренных кювет оба скачка наступают в пределах 100 min. Однако оказалось, что существует выделенный размер кюветы, для которого расстояние между окном кюветы и поверхностью мембраны равно $12 \mu \mathrm{m}$. В этом случае в течение $100 \mathrm{~min}$ полного схлопывания полости не происходит, и зависимость $\langle C(t)\rangle$ с высокой точностью описывается линейной функцией, причем тангенс угла наклона этой функции определяется степенью шероховатости окон кюветы. Оказалось, что в этом случае динамика $\langle C(t)\rangle$ очень чувствительна к внесению в жидкий образец внешних примесей, например $\mathrm{NaCl}$, причем отклонения от линейного характера зависимости $\langle C(t)\rangle$ наблюдаются вплоть до концентраций $\mathrm{NaCl}$ на уровне $10^{-14} \mathrm{M}$. Кроме того, линейный ход зависимости $\langle C(t)\rangle$ меняется после интенсивного встряхивания жидкого образца, но по прошествии определенного времени после встряхивания линейный ход восстанавливается. Эти особенности мы связываем с вкладом нанопузырьков в динамику схлопывания полости.

\section{Финансирование работы}

Работа поддержана грантом Министерства науки и высшего образования Российской Федерации на проведение крупных научных проектов по приоритетным направлениям научно-технического развития (грант № 075-15-2020-774).

\section{Конфликт интересов}

Авторы заявляют, что у них нет конфликта интересов.

\section{Список литературы}

[1] Mauritz K.A., Moore R.B. // Chem. Rev. 2004. V. 104. P. 4535.

[2] Liu L., Chen W., Li Y. // J. Membr. Sci. 2016. V. 504. P. 1.

[3] Wang Y., Chen K.S., Mishler J., Cho S.C., Adroher X.C. // Appl. Energy. 2011. V. 88. P. 981.

[4] Фролов Ю.Г. Курс коллоидной химии. Поверхностные явления и дисперсные системы. М.: Химия, 1988. 464 с.

[5] Pollack G.H. The Fourth Phase of Water. Seattle, WA, USA: Ebner and Sons Publishers, 2013.

[6] Ninham B.W., Lo Nostro P. Molecular Forces and Self Assembly in Colloid, Nano Sciences and Biology. Cambridge, NY., USA: Cambridge University Press, 2010.

[7] Bunkin N.F., Lyakhov G.A., Kozlov V.A., Shkirin A.V. etal. // Phys. Wave Phen. 2017. V. 25. P. 259.

[8] Bunkin N.F., Shkirin A.V., Kozlov V.A., Ninham B.W., Uspenskaya E.V., Gudkov S.V. // J. Chem. Phys. 2018. V. 149. P. 164901.

[9] Козлов В.А. Разработка экспериментальной установки и методик исследования изотопических эффектов при набухании протонообменной мембраны в смесях $\mathrm{H}_{2} \mathrm{O}-\mathrm{D}_{2} \mathrm{O}$ на основе фотолюминесцентной и инфракрасной фурьеспектроскопии. Автореф. канд. дис. М., 2018. 102 с.

[10] Craig H. // Science. 1961. V. 133. P. 1833. 
[11] Workman J. Jr., Weyer L. Practical Guide and Spectral Atlas for Interpretive Near-infrared Spectroscopy. CRC Press, 2013.

[12] Бункин Н.Ф., Балашов А.А., Шкирин А.В., Горелик В.С., Применко А.Э. и др. // Опт. и спектр. 2018. Т. 125. С. 324.

[13] Bunkin N.F., Kozlov V.A., Shkirin A.V., Ninham B.W., Balashov A.A., Gudkov S.V. // J. Chem. Phys. 2018. V. 148. P. 124901.

[14] Furst E.M., Squires T.M. Microrheology. Oxford University Press, 2017.

[15] Ingle J.D., Crouch S.R. Spectrochemical Analysis. N.J., Prentice Hall: Englewood Cliffs, 1988.

[16] Gebel G. // Polymer. 2000. V. 41. P. 5829.

[17] Бункин Н.Ф., Бункин Ф.В. // УФН. 2016. Т. 186. С. 933.

[18] Bunkin N.F., Shkirin A.V., Suyazov N.V., Babenko V.A., Penkov N.V., Belosludtsev K.N., Gudkov S.V. // J. Phys. Chem. B. 2016. V. 120. P. 1291 -1303.

[19] Yurchenko S.O., Shkirin A.V., Ninham B.W., Sychev A.A., Babenko V.A., Penkov N.V., Kryuchkov N.P., Bunkin N.F. // Langmuir. 2016. V. 32. P. 11245.

[20] Лобышев В.И., Томкевич М.С., Петрушанко И.Ю. // Биофизика. 2005. Т. 50. С. 464.

[21] Fang Z., Wang X., Zhou L., Zhang L., Hu J. // Langmuir. 2020. V. 36. P. 2264.

[22] Bunkin N.F., Shkirin A.V., Ninham B.W., Chirikov S.N., Chaikov L.L., Penkov N.V., Kozlov V.A., Gudkov S.V. // ACS Omega. 2020. V. 5. P. 14689.

[23] Alheshibri M., Qian J., Jehannin M., Craig V.S.J. // Langmuir. 2016. V. 32. P. 11086. 